\title{
South African teacher profiles and emerging teacher factors: The picture painted by PIRLS 2006
}

\author{
SURETTE VAN STADEN Centre for Evaluation and Assessment, \\ University of Pretoria \\ SARAH HOWIE Centre for Evaluation and Assessment, University of Pretoria
}

\begin{abstract}
The Progress in International Reading Literacy Study (PIRLS) assessment is an international comparative study of reading skills of Grade Four learners. South Africa's first participation in the study took place in the 2006 cycle (Mullis et al., 2007), with repeat participation planned to take place for PIRLS 2011. PIRLS 2006 results pointed to serious issues of under achievement among South African Grade Four learners, resulting in the adoption of the National Reading Strategy (Department of Education, 2008) and the Foundations for Learning Campaign. While some time has passed since the release of the PIRLS 2006 results, participation in PIRLS 2011 would highlight trends and possible progress made since the PIRLS 2006 study. This paper reports on the analysis of the Grade Four learner achievement in the PIRLS 2006 assessment into the teacher characteristics, use of resources and instructional practices and analyses of the PIRLS 2006 Teacher Questionnaire data. The main findings outlined by this paper reflects the need for teachers' continued professional development at Intermediate Phase, the need to employ strategies to retain young teachers and the importance of making available good quality reading materials to schools.
\end{abstract}

\section{Introduction}

In the last decade, South African teachers have faced extensive changes to the education system and South Africa has successfully produced many policy (including curricula) documents, but has been less successful in implementing them. To add to the difficulties of implementation, there are many differences between schools in South Africa, and, after thirteen years of democratic rule, schools that were previously designated for White learners only are still elite schools compared to those that were previously disadvantaged under the Apartheid system. Johnson, Monk and Hodges (2000) are of the opinion that 
South Africa effectively still has separate education systems operating within the country in light of the starkness of continuing differences in teacher education and educational provision. Fleisch (2007) also reflects on this in his description of the country having two nations. Howie (2001) earlier described South Africa as containing features of both richer countries and poorer countries with regard to its education system.

Notwithstanding these continuing variances in education provision, the national Department of Education views teachers as key contributors to transformation in South Africa. In the 'Revised National Curriculum Statement' (Department of Education, 2002), the Department presented a vision of teachers who are qualified, competent, dedicated and caring. Teachers' roles and functions are seen to include being mediators of learning, interpreters and designers of Learning Programmes and materials, leaders, managers, administrators, scholars, researchers, lifelong learners, community members and citizens, and assessors and Learning Area or Phase specialists. In the next section, in the light of the above, the literature on teacher effectiveness is reviewed, on the assumption that teacher effectiveness is a critical component of the education system.

\section{Literature review on teacher effectiveness}

Ongoing concerns about the development of learners' literacy skills in South Africa drive the literacy teaching and learning research landscape. These include: concerns associated with school students' development of basic literacy skills at the foundational levels of education (Bloch, 1999, Lessing and de Witt, 2005); concerns about students' acquisition of more advanced literacy skills in high school (Matjila and Pretorius, 2004, Pretorius and Ribbens, 2005); and concerns about the development of the advanced literate language skills needed for tertiary level education (Pretorius, 2002). Such concerns are consistently reflected in local research (see Howie et al., 2007).

With regards to school-related factors impacting on the reading achievement of learners, Howie (2006) reports a number of factors specifically related to learners in South African classrooms. These factors include inadequate subject knowledge of teachers, inadequate communication between learners and teachers in the language of instruction, lack of instructional materials, teachers' abilities to manage classroom activities effectively and overcrowded classrooms. These factors are also highlighted by the Department of Education (2008). 
Sailors, Hoffman and Matthee (2007), in their evaluation of schools that promote literacy learning in low-income communities, summarized the work of a number of researchers (such as Weber, 1971, Hoffman and Rutherford, 1984) who identify themes across effective schools that could guide reform efforts in failing schools that operate in resource-poor environments. The common themes in these schools that influenced learner achievement positively included: a clear school mission, effective instructional leadership and practices, high expectations for learners to achieve and perform at their best, a safe, orderly, positive physical environment, ongoing curriculum improvement, maximum use of available instructional time, frequent monitoring of learner progress and positive home-school connections.

Following their work on high-achieving schools from low-income environments in a sample of South African primary schools, Sailors et al. (2007) identified their own set of themes and factors that seem to impact positively on learner achievement. Dovetailing with the work of other researchers, they cite the presence of a safe, orderly learning environment as having a positive influence on learner achievement. Another factor identified includes the presence of strong leadership that guides the school in terms of academic guidance, community relations and shared decision making. In describing teachers as 'excellent', a third factor is identified that impacts learner achievement positively, where teachers are characterized as committed, competent, caring and collaborative. A fourth identified factor is that of a shared sense of competence, pride and purpose in schools that function effectively in lowincome communities. Lastly, community participation and engagement with the school constitutes a factor associated with higher achievement among learners (Sailors et al., 2007).

Classroom teaching for reading instruction needs to be considered as the critical factor in preventing reading problems and must be the central focus for change (Moats, 1999). Teachers' acquisition of the teaching skills necessary to bring about the development of literate language competency are critical, (Zimmerman, 2008) especially as, in South Africa, many assumptions have been largely unquestioned about how to teach reading and writing, which languages to use and what counts as high quality practice in classrooms (Bloch, 1999). Stoller and Grabe (2001) emphasize that the requirements for the development of reading fluency necessitate that teachers as well as curriculum developers determine what instructional options are available to them and how to go about the optimal pursuit of instructional goals in various contexts. 


\section{Data sources and analysis}

The main data source for this paper is the PIRLS 2006 database for Grade Four (Mullis et al., 2007). The PIRLS 2006 assessment consisted of a reading assessment, and in addition to that, contextual questionnaires that were administered to school principals, teachers, parents and learners. For the purposes of reporting results, this paper utilized the data obtained from the teacher questionnaires, as completed by teachers of Grade Four learners who participated in the PIRLS 2006 assessment.

Data analysis in this paper is limited to examining results of descriptive statistics to Grade Four learners' teachers' responses. These results are provided against the background of South Africa's overall performance in PIRLS 2006 compared internationally, as is reported in the PIRLS 2006 International Report and Grade Four learner overall performance in particular.

\section{South Africa's overall reading achievement compared internationally}

A total of forty countries and forty-five education systems participated in PIRLS 2006. The International Association for the Evaluation of Educational Achievement (IEA) released the PIRLS 2006 international reading literacy achievement results on 28 November 2007 at Boston College in the United States of America. The results provided overall reading averages achieved by each participating country. Through the use of Item Response Theory (IRT) scaling, the PIRLS 2006 average is set at a fixed 500 points with a standard deviation of 100 points. Participants' achievements are therefore placed relative to the international mean of 500. Appendix A provides the distribution of reading achievement as taken from the PIRLS 2006 International Report (Mullis et al., 2007).

Internationally, PIRLS 2006 required the assessment of learners who have had four years of schooling and for most countries this requirement translated to Grade Four learners. The South African PIRLS 2006 study assessed this first population of Grade Four learners, but also included a second population of Grade Five learners as a national option included in the study. Appendix A indicates that South Africa achieved the lowest score of the forty-five participating education systems. Appendix A also indicates that the international report only provides results for South Africa's Grade Five population. With an 
average age of 11.9 years, the South African learner population was the oldest across all participating countries. Grade Four learners achieved on average 253 points $(\mathrm{SE}=4.6)^{1}$, while Grade Five learners achieved on average 302 (5.6). Average achievement for both these Grades is well below the fixed international average of 500 points. Closest to South Africa in reading achievement was Morocco, the only other African country that participated in PIRLS 2006, with a Grade Four average of 323 points (5.9).

According to PIRLS 2006, South Africa had the highest infant mortality rate (53 per 1000 live births), the lowest life expectancy (46 years) and the highest learner-to-teacher ratio of all the participating education systems. In terms of budgetary expenditure on education as a percentage of the Gross Domestic Product (GDP), South Africa is ranked average in comparison to the expenditure on education by other countries (Howie et al., 2007).

\section{South Africa's overall achievement for Grade Four learners nationally by language}

The PIRLS 2006 reading assessment was administered to a sample of 16,073 Grade Four learners in all eleven official languages in South Africa. It has to be kept in mind that the results for each language are in terms of the language of the test, not home language. Children were tested in the language in which they had been receiving instruction for the first three years of formal schooling. Average achievement scores that are provided here per language are therefore for learners who completed the assessment in the language of the test (the language that should have coincided with the language in which the learner has been receiving instruction for the first three years of schooling), and may therefore be different from the learner's home language.

Figure 2 indicates that the learners who wrote the PIRLS 2006 assessment in Afrikaans achieved the highest average score of 351.70 (12.04), closely followed by learners who completed the assessment in English (346.82, SE=17.46). Learners who completed the assessment in African languages achieved well below 300 points, with Setswana learners achieving the highest scores, while IsiNdebele and IsiXhosa learners achieved the lowest average scores at 176.80 (9.02) and 189.97 (6.50) respectively. All South African achievement scores were well below the international average of 500 points.

${ }^{1}$ SE stands for Standard Error and refers to the extent of deviation of the sampling distribution from the standard. e.g., where $\mathrm{SE}$ is given as 4.6, the extent of deviation can be interpreted as small relative to the sample size. Note that the numbers in brackets that follow also refer to SE scores. The initials $\mathrm{SE}$ are left out after the first instance for convenience sake, in keeping with common practice in statistical reports. 


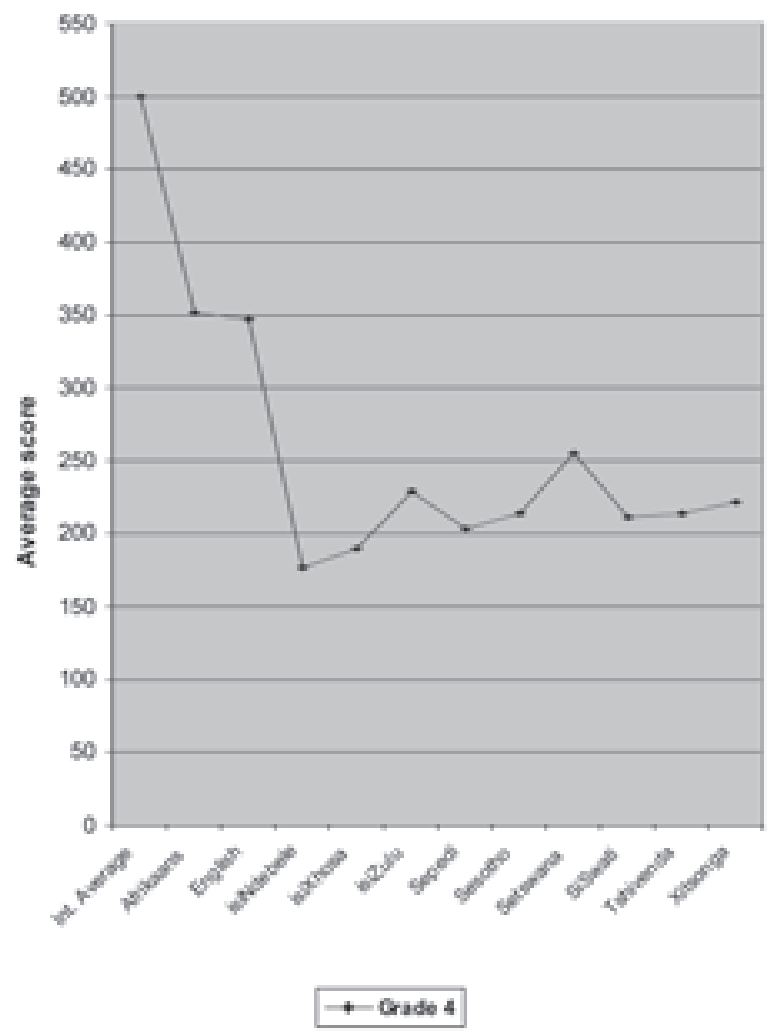

Figure 2: Average achievement according to language for Grade Four

\section{Teacher characteristics, use of resources and instructional practices}

In light of the dismally low reading achievement scores for Grade Four learners, further enquiry is needed into teacher characteristics, use of resources and instructional practices. The teachers who taught the Grade Four South African sample students completed the PIRLS 2006 Teacher Questionnaire. These teachers had on average fifteen years of teaching experience, and, more specifically, 6 years (0.4) of Grade Four teaching experience (Howie et al., 2007). In terms of gender, Grade Four learners were taught by a majority of female teachers at $84.19 \%$ with the remaining $15.81 \%$ of the sample made up of male teachers. Of concern is that there was a very small percentage of young, up-and-coming teachers. Only $1 \%(0.6)$ of learners were taught by teachers who were younger than twenty-five years old, with only another $4 \%(1.4)$ being between the ages of twenty-five to twenty-nine years (see Table 1 below). 
While the number of students studying to be teachers is fairly substantial at tertiary teacher education institutions across South Africa, the high incidence of teacher attrition rates is problematic. Some (often White) young teachers prefer to leave South Africa for more lucrative teaching positions overseas, or merely choose to leave the profession after only a short period of teaching.

The average achievements for Grade Four learners taught by teachers under the age of twenty-five years $(461,52.4)$ and teachers over the age of sixty years $(432,64.7)$ were higher than the average achievement obtained for any other groups of learners based on their teachers' ages (Howie et al., 2007). The two groups of youngest and oldest teachers, whose Grade Four learners achieved the highest average scores, represent the smallest percentages of Grade Four teachers for this sample, and this can be seen as a matter of concern. Larger percentages of teachers in the remaining age groups achieved the lowest average achievement on the PIRLS 2006 assessment.

Table 1 provides a breakdown of average achievement by Grade Four learners on the PIRLS 2006 reading assessment categorising the age of their teachers:

\begin{tabular}{l|r|r|c|c}
\hline \multicolumn{1}{c|}{ Teachers Age } & \multicolumn{1}{c|}{ N } & \% & SE & $\begin{array}{c}\text { Average PIRLS 2006 } \\
\text { Reading Achievement }\end{array}$ \\
\hline Under 25 & 94 & 0.93 & 0.56 & 461.03 \\
\hline 25-29 years & 291 & 3.67 & 1.40 & 261.32 \\
\hline 30-39 years & 5537 & 36.68 & 2.90 & 237.11 \\
\hline 40-49 years & 6792 & 41.15 & 2.86 & 255.09 \\
\hline 50-59 years & 2420 & 17.47 & 2.33 & 255.75 \\
\hline 60-69 years and older & 77 & 0.11 & 0.09 & 432.07
\end{tabular}

Table 1: Average PIRLS 2006 achievement for teachers' age groups

\section{Teachers' formal education and training}

The highest percentage of South African learners $(41 \%, 3.7)$ was taught by teachers with a three-year college diploma. Of these learners, $60 \%$ (3.2) were taught by teachers with a teaching certification from the former teacher training colleges or were in possession of a post-matric certificate (Howie et al., 2007). A little over $14 \%$ of learners had language teachers who reported to have postgraduate degrees - these learners achieved a higher average compared to those learners whose teachers had no postgraduate qualifications.

When asked about knowledge domains or subject areas of specialization, teachers of Grade Four learners reported exposure to training that focused 
on language, literature, pedagogy, teaching reading, psychology, children's language development and second language learning. Approximately 50\% (3.2) of South African learners had teachers who reportedly received training where second-language learning received major emphasis.

Amongst special education and remedial reading learners, teachers reported to have little to no training in these areas. For 40\% (3.2) of the teachers of Grade Four learners remedial reading was only covered in an introductory fashion during training, while an additional $39 \%$ of teachers reported to have had no exposure to remedial reading at all. Given the students' low achievement in reading literacy and the extent of learner variation at classroom level, the dearth of remedial reading training received by teachers is a cause of concern.

\section{Instructional materials}

Amongst the teachers of Grade Four learners, 57\% (2.6) reported using textbooks everyday or almost everyday. Only $12 \%$ (1.8) of Grade Four learners had teachers who reported using a variety of children's books for reading instruction every day or almost every day (Howie et al., 2007). A notable anomaly was the higher average achievement of learners whose teachers reported to never using textbooks $(375.32,45.9)$ compared to their counterparts who reported monthly $(339.16,37.53)$ or daily use of textbooks $(235,5.2)$.

The reliance on textbooks by a large percentage of teachers of Grade Four learners must be seen within the context of teaching in many schools in South Africa. Not only are textbooks often the only source available to the teacher as an aide to teaching reading, but the quality of these books is sometimes a concern. Anecdotal evidence gathered specifically during school visits in rural areas points to the fact that many outdated Afrikaans and English textbooks have been handed down to rural schools. In some cases, these books can be found unused on shelves, but equally alarmingly, cases exist where these outdated books are being put to use. In addition, teachers often rely on preserving limited resources of textbooks to the extent that learners are not permitted to take these books home for fear of damage or loss. Thus, learners' only exposure to books in poorly resourced schools is often only in the form of textbooks, and then only for the limited time the learner is present in class.

\section{Instructional strategies and activities}

Most children in South African schools are reportedly exposed to certain reading skills only, during the Foundation Phase (Grades 1 to 3), such as decoding strategies and understanding vocabulary. According to Pretorius (2002), the 
Intermediate Phase (Grades Four to Six) affords learners the opportunity to use reading as a language- and information-processing skill, as learners are largely expected to be able to decode text. At Grade Four, learners should also begin the switch from learning the 'lower level' skills involved in learning to read, and to adapting those skills in order to use reading as a tool to learn. Twenty five per cent (2.4) of Grade Four learners in the PIRLS 2006 report have teachers who engage them daily in decoding strategies, compared to $69 \%$ (0.5) of teachers of Grade Four learners internationally.

In terms of time allocated to reading activities in the classroom, more than half the Grade Four learners $(61 \%, 2.9)$ had teachers who reported reading aloud to the whole class every day or almost every day. For these learners, this reading is the most prominent activity listed by teachers. Of concern is the fact that reading aloud to the class is a teacher-centred approach where learners are only involved passively and where the teacher mostly assumes that learners are able to follow and able to understand what is being read. Also of concern are the low frequencies at which learners are afforded the opportunity to read independently. Indeed, 7\% (1.7) of teachers of Grade Four learners indicated that the learners never or almost never engaged in independent reading in class, with only $27 \%$ (2.7) reporting reading independently as little as once or twice a month (Howie et al., 2007). Learner achievement was highest $(299.3,12.5)$ for those learners' teachers who reportedly afforded learners the opportunity to read silently everyday or almost everyday. Given the lack of opportunity afforded to Grade Four learners to read independently, it would be understandable that the format of the PIRLS 2006 reading assessment (consisting of reading booklets composed of reading passages for each child individually) might have been an intimidating and alien experience for many South African Grade Four learners.

\section{Instructional time}

Despite South African Grade Four learners' poor performance in the PIRLS 2006 reading assessment, the majority of teachers of Grade Four learners $(50.37 \%, 3.06)$ indicated that they regarded the reading levels of their learners to be average. Only $6.04 \%$ (1.72) of teachers reported reading levels to be below average.

The PIRLS 2006 international report indicates that on average internationally teachers allocated $30 \%$ of instructional time to language instruction and $20 \%$ to reading instruction (Mullis et al., 2007). On average, internationally, Grade Four learners were taught explicit reading instruction for more than 6 hours a week. Teachers' reports in the South African study reveal that 10\% (1.9) of 
Grade Four learners received reading instruction for more than 6 hours per week, $18 \%$ (2.7) for between 3 and 6 hours and 72\% (2.7) for less than 3 hours per week. From these data, it becomes clear that South African reports fall far below the international averages in terms of time spent on reading instruction.

A third of the learners' teachers reported engaging in reading instruction every day, but little direct relationship can be found between reported time spent on reading instruction and reading achievement. A multitude of variables influence learners' reading achievement and time spent on reading instruction is not necessarily a stand-alone indicator of the quality of the activities in which learners are engaged.

\section{Class size and instructional activities}

The average Grade Four class size included in the South African PIRLS 2006 study was 46 (0.12) learners, the highest of the participating countries and higher than the international average class size of 24 learners. Table 2 indicates South African class sizes in comparison to overall average reading achievement:

\begin{tabular}{l|c|c|c}
\hline \multicolumn{1}{c|}{ Class Size } & $\%$ & SE & $\begin{array}{c}\text { Average } \\
\text { Achievement }\end{array}$ \\
\hline 1-10 Learners & 0.14 & 00 & 165.57 \\
\hline 11-20 Learners & 2.89 & 0.86 & 277.26 \\
\hline 21-30 Learners & 13.68 & 1.99 & 351.13 \\
\hline 31-40 Learners & 27.41 & 2.52 & 258.92 \\
\hline 41-50 Learners & 32.87 & 3.13 & 235.96 \\
\hline 51-60 Learners & 15.26 & 1.89 & 219.30 \\
\hline 61-70 Learners & 3.68 & 1.13 & 213.96 \\
\hline 71-80 Learners & 1.20 & 0.62 & 176.90 \\
\hline 81 Learners and above & 2.89 & 1.05 & 186.39
\end{tabular}

Table 2: Overall average achievement in comparison to class size

As indicated by Table 2, the highest overall average achievement was obtained by those Grade Four learners in classes with between 21 and 30 students. With more than 40 students per class, achievement drops markedly to as low as 186.39 for learners in classes of extreme sizes of 81 or more children.

In terms of reading activities in the classroom, teachers of Grade Four learners reported most commonly reading aloud to the class when teaching reading 
instruction or engaging with the learners in reading activities. Figure 3 shows the percentages of activities teachers reported to engage with learners every day:

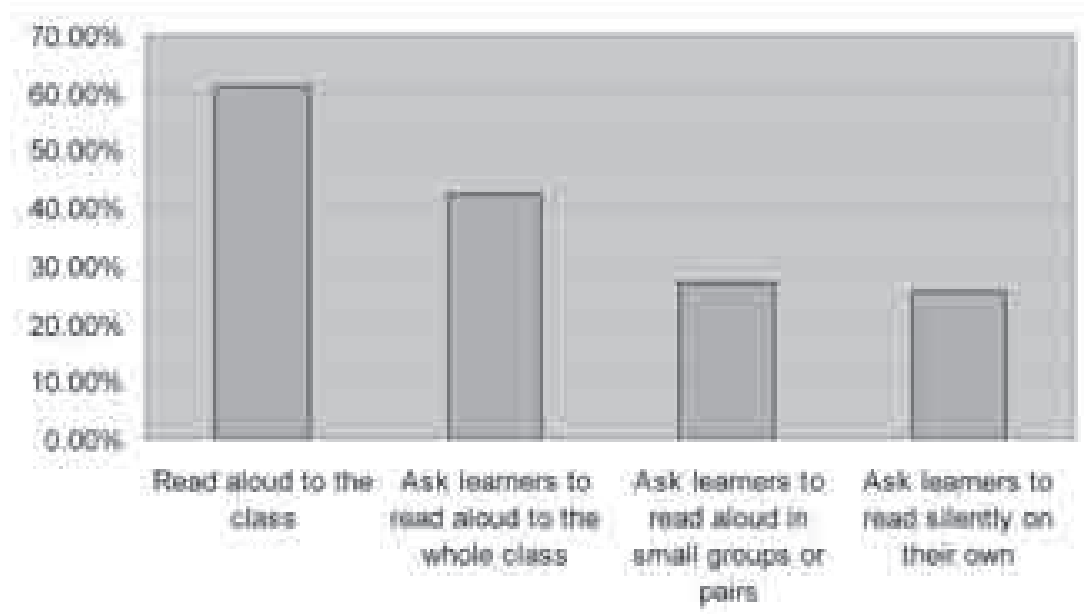

Figure 3: Teacher engagement in everyday reading activities

Figure 3 supports findings discussed below concerning teachers' instructional strategies and activities, and illustrates that teachers reportedly spent most time in reading aloud to the class themselves $(61 \%, 2.9)$. Alarmingly, silent reading took place least frequently of all the listed everyday reading activities in this sample of South African classrooms. Top performing countries in PIRLS 2006 report much higher frequencies of silent reading activities, with 84\% (2.9) of teachers from the Russian Federation and 85\% (3.2) of teachers from Canada, Alberta, reporting silent reading as a daily activity.

\section{Conclusions and implications}

South African Grade Four learner-achievement in the PIRLS 2006 study accentuates the need for reading instruction practices aimed at addressing the difficulties South African learners encounter in both the Foundation and Intermediate Phases. As stated in the International Reading Association's (2007: 1) synthesis on their research into teacher preparation for reading instruction "putting a quality teacher in every classroom is key to addressing the challenges of reading achievement in schools. Knowledgeable, strategic, adaptive, and reflective teachers make a difference in student learning." 
The teacher data presented in this paper indicates the need for Intermediate Phase teachers' continuous professional development, as Grade Four learners' low overall achievement scores, in relation to teacher qualifications, suggests that these teachers have not been adequately prepared to teach reading literacy. Of concern is the high incidence of low achievement among learners who are taught by teachers aged between thirty and fifty-nine years. The data highlights the need for strategies to retain the younger demographic of up-and-coming teachers, whilst tapping into the knowledge and experience of teachers closer to retirement and exiting from the system.

The data presented here leads to questions concerning the quality and availability of reading materials and how these are used in the Intermediate Phase. Specifically, it seems that more investigation is needed into the quality and content of textbooks and the quality of teaching where textbooks are used as only or main source of reading instruction.

While the effect of class sizes on reading achievement is illustrated by the PIRLS 2006 data, of concern is also the little time that is reportedly spent on explicit reading instruction. Compared internationally, South African Grade Four teachers spend on average far less time on frequent reading instruction. Coupled with this low frequency of time on task is also the relative low quality of associated reading activities. While the majority of teachers report to spending a lot of time reading out aloud to the class as a whole, the nature of this activity is not an effective gauge of the levels of understanding of what is being read, nor does it effectively allow for learners to become independent readers.

While more interrogation into the PIRLS 2006 achievement data and questionnaire data is required, this paper provides preliminary evidence of teacher reports about aspects such as the use and availability of resources, and the nature of reading activities and instructional practices that most often tend to take place in Grade Four classrooms around South Africa. The inadequacies of Intermediate Phase teacher preparation and lack of explicit time spent on reading instruction may well reflect inadequacies at Foundation Phase and perhaps even at the pre-primary stage, as well as the lack of pre-primary education, in many cases.

\section{References}

Bloch, C. 1999. Literacy in the early years: Teaching and learning in multilingual early childhood classrooms. International Journal of Early Years Education, 7(1): 39-51.

Department of Education. 2002. Revised National Curriculum Statement, Grades R-9. Government Gazette, 443, 23406, May. 
Department of Education. 2008. National Reading Strategy. Pretoria: Department of Education.

Fleish, B. 2007. Primary education in crisis: Why South African schoolchildren underachieve in reading and mathematics. Cape Town: Juta and Company.

Howie, S.J. 2001. Mathematics and Science Performance in Grade 8 in South Africa 1998/1999: TIMSS R. HSRC Report: Pretoria.

Howie, S.J. 2006. Multi-level factors affecting the achievement of South African pupils in mathematics. In: Howie, S.J. and Plomp, T. (eds). Contexts of Learning and Science. Oxon: Routledge, 71-9.

Howie, S.J., Venter, E., van Staden, S., Zimmerman, L., Long, C., Scherman, V. and Archer, E. 2007. PIRLS 2006 Summary Report: South African Children's Reading Literacy Achievement. Pretoria: Centre or Evaluation and Assessment.

International Reading Association (IRA). 2007. Teaching Reading well. A synthesis of the International Reading Association's research on teacher preparation for reading instruction. Newark, DE: International Reading Association. Downloaded in March 2008 from www.reading.org.

Johnson, S., Monk, M. and Hodges, M. 2000. Teacher Development and Change in South Africa: A Critique of the Appropriateness of Transfer of Northern/Western Practice. Compare: A Journal of Comparative Education, 30(2): 179-192.

Lessing, A.C. and de Witt, M.W. 2005. An investigation into the early literacy skills of Grade R second-language (L2) learners in South Africa. Africa Education Review, 2(2): 242-257.

Matjila, D.S. and Pretorius, E.J. 2004. Bilingual and biliterate? An exploratory study of grade 8 reading skills in Setswana and English. Per Linguam, 20(1): 1-21.

Moats, L.C. 1999. Teaching reading is rocket science. What expert teachers of reading should know and be able to do. Report for the American Federation of Teachers. Item no. 39-0372. Downloaded in April 2007 from http://www.aft.org/pubs-reports/ downloads/teachers/rocketsci.pdf.

Mullis, I.V.S., Martin, M.O., Kennedy, A.M., and Foy, P. 2007. PIRLS 2006 International Report: IEA's Study of Reading Literacy Achievement in Primary Schools. Chestnut Hill: Boston College.

Pretorius, E.J. 2002. Reading ability and academic achievement in South Africa: Are we fiddling while Rome is burning? Language Matters, 33: 169-196.

Pretorius, E.J. and Ribbens, R. 2005. Reading in a disadvantaged high school: Issues of accomplishment, assessment and accountability. South African Journal of Education, 25(3): 139-147.

Sailors, M., Hoffman, J.V. and Mathee, B. 2007. South African schools that promote literacy learning with students from low-income communities. Reading Research Quarterly, 42(3): 364-387.

Stoller, F.L. and Grabe, W. 2001. Action research as reflective teacher practice in the context of L2 reading classrooms. Tydskrif vir Taalonderrig, 35(2\&3): 97-109.

Zimmerman, L. 2008. Unpublished PhD proposal. PhD Assessment and Quality Assurance, Faculty of Education, University of Pretoria. 


\section{Appendix A}

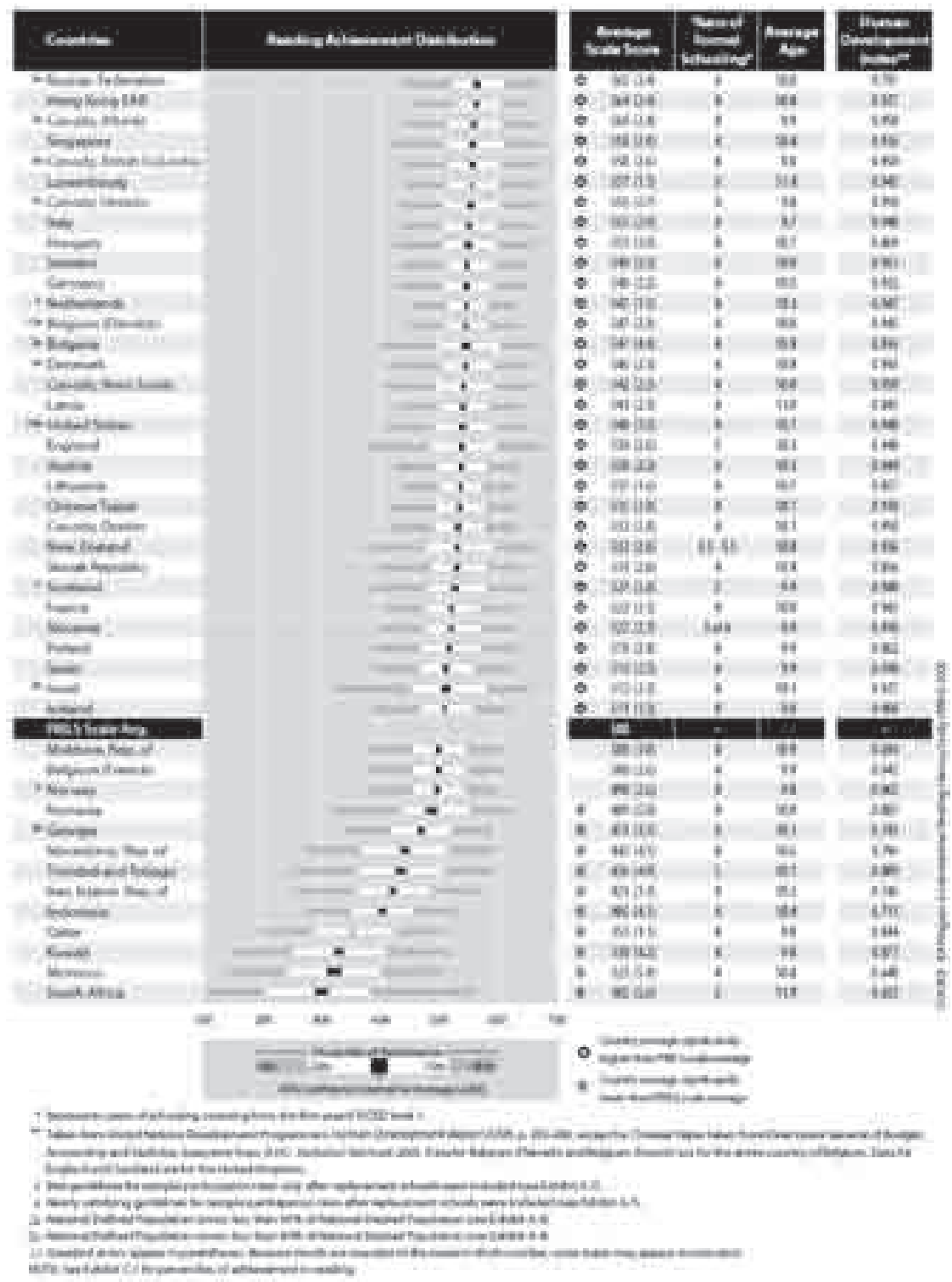

